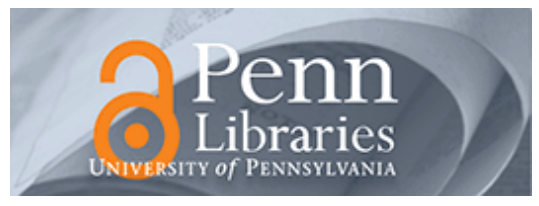

University of Pennsylvania

ScholarlyCommons

Marketing Papers

Wharton Faculty Research

6-2009

\title{
Using Quasi-Experimental Data to Develop Empirical Generalizations for Persuasive Advertising
}

\author{
J. Scott Armstrong \\ University of Pennsylvania, armstrong@wharton.upenn.edu \\ Sandeep Patnaik \\ Gallup and Robinson
}

Follow this and additional works at: https://repository.upenn.edu/marketing_papers

\section{Recommended Citation}

Armstrong, J. S., \& Patnaik, S. (2009). Using Quasi-Experimental Data to Develop Empirical Generalizations for Persuasive Advertising. Retrieved from https://repository.upenn.edu/ marketing_papers/167

Suggested Citation:

Armstrong, J.S. and Patnaik, S. (2009). Using Quasi-Experimental Data to Develop Empirical Generalizations for Persuasive Advertising. Journal of Advertising Research. Vol. 49(2). p. 170-175.

The definitive version of this article is available at: http://www.journalofadvertisingresearch.com/ArticleCenter/ default.asp?ID=89489\&Type=Article

This paper is posted at ScholarlyCommons. https://repository.upenn.edu/marketing_papers/167

For more information, please contact repository@pobox.upenn.edu. 


\title{
Using Quasi-Experimental Data to Develop Empirical Generalizations for Persuasive Advertising
}

\begin{abstract}
This paper argues that "quasi-experimental data" provide a valid and relatively low-cost approach toward developing empirical generalizations (EGs). These data are obtained from studies in which some key variables have been controlled in the design. These EGs are described as normative statements, i.e., "evidence-based principles." Using data from 240 pairs of print advertisements from five editions of the Which Ad Pulled Best series, the authors analyzed 56 of the advertising principles (listed) from Persuasive Advertising by J. Scott Armstrong (New York: Palgrave Macmillan, forthcoming). These data controlled for target market, product, size of the advertisement, media, and in half the cases, for the brand. The advertisements differed, however, e.g. in illustrations, headlines, and text. The findings from the quasi-experimental analyses were consistent with field experiments for all seven principles where such comparisons were possible. Furthermore, for 26 principles they unanimously corroborated the available laboratory experiments as well as the meta-analyses for seven principles. In short, the quasiexperimental findings always agreed with experimental findings, even though the quasi-experimental analyses, and some of the experimental analyses, involved small samples, and often used different criteria. From an issue of JAR devoted to 'empirical generalisations': the papers were first presented at a conference at the Wharton School, University of Pennsylvania in December 2008.
\end{abstract}

\section{Comments}

Suggested Citation:

Armstrong, J.S. and Patnaik, S. (2009). Using Quasi-Experimental Data to Develop Empirical Generalizations for Persuasive Advertising. Journal of Advertising Research. Vol. 49(2). p. 170-175.

The definitive version of this article is available at: http://www.journalofadvertisingresearch.com/ ArticleCenter/default.asp?ID=89489\&Type=Article 


\section{Using Quasi-Experimental Data To Develop Empirical Generalizations For Persuasive Advertising}

J. SCOTT ARMSTRONG The Wharton School armstrong@wharton. upenn.edu

\section{SANDEEP PATNAIK}

Gallup and Robinson sandeep.patnaik@ gallup-robinson.com

"Quasi-experimental data" provide a valid and relatively low-cost approach toward developing empirical generalizations (EGs). These data are obtained from studies in which some key variables have been controlled in the design. We describe our EGs as "evidence-based principles." Using data from 240 pairs of print advertisements from five editions of the Which Ad Pulled Best series, we analyzed 56 of the advertising principles from Persuasive Advertising by J. Scott Armstrong (New York: Palgrave Macmillan, forthcoming). These data controlled for target market, product, size of the advertisement, media, and in half the cases, for brand. Aspects of the advertisements differed, however, as in illustrations, headlines, color, and text. The findings from quasi-experimental analyses were consistent with field experiments for all seven principles where such comparisons were possible. Furthermore, for 26 principles they unanimously corroborated the available laboratory experiments as well as the meta-analyses for seven principles. In short, quasi-experimental findings always agreed with experimental findings. This is impressive given that the quasi-experimental analyses-and some of the experimental analyses_involved small samples, and often used different criteria.

\section{INTRODUCTION}

Progress in advertising depends upon the use of cumulative knowledge. This knowledge can be transformed into empirical generalizations (EGs). In this article, we discuss a type of EG that we refer to as "evidence-based principles," or, more simply, as principles.

We describe the types of evidence that can be used to develop principles. We then describe the quasi-experimental data on full-page print advertisements that we used to assess advertising principles. Finally, we examine the validity of the analyses of these data by comparing the findings with those from other types of studies including laboratory experiments, field experiments, and meta-analyses based on experimental evidence.

\section{SOURCES OF EVIDENCE}

Nonexperimental studies involve analyses of data on a set of advertisements to determine which variables are most closely related to success. This is probably the dominant way by which people draw inferences about the value of persuasive strategies in advertising.

In quasi-experimental studies, the design controls for some (but not all) variables when comparing different advertisements. For example, these studies might compare advertisements for a given brand and media. Other variables, however, may not be controlled. This approach is seldom used to analyze persuasive advertising.

In experimental studies, the values of all key causal variables are controlled. For example, a researcher who wants to know whether humor is 


\section{EMPIRICAL GENERALIZATION}

Communicate a unique selling proposition. Ideally, it should be based on an important benefit; alternatively, and riskier, it could be based on a feature that clearly implies a benefit. It is effective if it is unique in the minds of consumers even though other brands could make the same claim. However, it is especially effective if it cannot be easily matched by competitors. This generalization, previously regarded as problematic, is supported by recent experimental evidence.

persuasive creates two identical advertisements, except that one advertisement is humorous and the other is not. The researcher shows the advertisements to randomly assigned subjects in identical situations and records their reactions. Experimental evidence comes from two types of studies: laboratory experiments and field experiments. The former allows for tighter control, while the latter adds realism.

\section{ANALYSIS OF THE WAPB QUASI-EXPERIMENTAL DATABASE}

We analyzed full-page print advertisements from Which Ad Pulled Best (WAPB) 5th through 9th editions (Burton and Purvis, 1987-2002). Each edition contains 50 pairs of advertisements (except for the 9th edition, which has 40 pairs). These advertisements had been prepared by leading U.S. advertisers and were then sent for testing by Gallup \& Robinson. In effect, they represent quasi-field experiments. The advertisements featured in $W A P B$ 5th through 8th editions are archived at www.advertisingprinciples. com. WAPB 9th edition is archived at www.gallup-robinson.com

\section{Criteria}

The WAPB criteria for these quasiexperimental data relate to recall. Recall is an intermediate step; if you are not aware of an advertisement, you are unlikely to act on it. Zinkhan and Gelb (1986) found that high "noted" scores were positively related to purchase intentions ( $r=0.52$ ).
The WAPB database allows testing of the direction and effect size for the advertising principles because most of the conditions were identical for each advertisement in the pairs. The target market, product, and media were the same. Of the 240 pairs of advertisements, 123 were paired against the same brand. Aspects of the advertisements differed, however, such as in illustrations, headlines, color and text.

Instructors' guides for each WAPB edition provided recall scores for advertisements in 40 of the pairs and reader-interest scores for 10 pairs. (Reader-interest scores were not included in the 9th edition.) We consider both of these scores under the term "recall." Recall scores were based on a subject's ability to identify both the product and advertiser the day following exposure.

\section{Coding the advertisements}

A team of research assistants coded the conditions and actions for each advertisement. In some cases (i.e., "How many words are in a headline"), the coding was straightforward. In many cases, however, the coding was subjective (i.e., determining whether an advertisement related to a high-involvement or low-involvement product). Someone familiar with the principle, therefore, had to be charged with thoughtfully doing the coding. The coders, however, had no knowledge of the purpose of the coding.
In some cases, the advertisements were coded by more than one person. For example, advertisements for one principle, "Communicate a Unique Selling Proposition (USP)," were coded by three coders to establish that the coding related to a USP and not merely to a benefit. The coders were asked to keep notes regarding uncertainty or other observations relevant to their coding decision.

Coding sheets were prepared (sample sheets are provided at advertisingprinciples.com). All coding was done prior to viewing the criteria, except for two principles in the early stages, when the procedure was being developed. The process meant that no coders had prior knowledge regarding an advertisement's degree of effectiveness.

In a number of instances, the advertisements were coded several times to examine the main principle and the conditions associated with the principle. For example, while coding for the principle "Communicate a USP," our initial analysis yielded 18 pairs in which one advertisement in the pair claimed a USP while the other did not make such a claim. Next, all advertisements with USP claims were carefully coded to check whether their USPs could have been claimed by other products or services. We found 27 pairs of advertisements where one of the advertisements had a USP that could not have been claimed by any other product while the other advertisement stated a common USP. In general, advertisements with USPs that were not common were better recalled than advertisements using a "common" USP. For example, an advertisement for Norland Bone Desensitometer that said "Unique design of the scanner allows scans anywhere on the surface of the table, and at any angle. Your patient does not move, the scanner arm does.... No other system offers this feature" had a recall thrice that for another 


\section{TABLE 1}

\section{Quasi-Experimental Results on Recall Gain for Persuasion Principles}

\begin{tabular}{|c|c|c|}
\hline $\begin{array}{l}\text { Recall } \\
\text { Gain }\end{array}$ & $\begin{array}{l}\text { Number of } \\
\text { Advertising } \\
\text { Pairs }\end{array}$ & Description of Principles: I ncludes Necessary Conditions \\
\hline 2.12 & 6 & Offer verifiable evidence. \\
\hline 2.04 & 45 & Communicate a Unique Selling Proposition (USP) (one that cannot be claimed by other brands). \\
\hline 1.74 & 46 & Make the first paragraph relevant \\
\hline 1.73 & 10 & Describe a problem and show how the product solves it. \\
\hline 1.71 & 21 & Include brand and company names (double-branding). \\
\hline 1.65 & 10 & Consider celebrity endorsements for gaining attention. \\
\hline 1.64 & 20 & Provide news, but only if it is real. \\
\hline 1.60 & 24 & Use positive arguments. \\
\hline 1.54 & 43 & Illustrations should support the basic message. \\
\hline 1.52 & 24 & Use descriptive headlines for high-involvement products. \\
\hline 1.50 & 36 & Balance the layout. \\
\hline 1.49 & 24 & Include the brand name in the headline. \\
\hline 1.48 & 25 & For high-involvement products, the reasons should be strong. \\
\hline 1.44 & 22 & Consider mystery advertisements only when the brand or organization does not enhance the claim. \\
\hline 1.44 & 18 & Make the brand or company name prominent if it conveys a good image. \\
\hline 1.43 & 14 & Show the product. \\
\hline 1.42 & 12 & Make elements of an advertisement reinforce one another. \\
\hline 1.39 & 12 & Use product-related questions only if you have good answers. \\
\hline 1.34 & 37 & Provide product information that customers need. \\
\hline $\begin{array}{l}1.34 \\
\ldots \ldots \ldots \ldots\end{array}$ & 37 & When using metaphors, make them concrete. \\
\hline 1.32 & 38 & Use concrete words. \\
\hline 1.32 & 14 & Use familiar words. \\
\hline $\begin{array}{l}1.31 \\
\ldots \ldots \ldots . . . .\end{array}$ & $\begin{array}{l}7 \\
\ldots . . .\end{array}$ & Provide evidence that the product is widely used. \\
\hline 1.29 & 37 & Provide a reason. \\
\hline 1.28 & 16 & Use a typeface to enhance meaning. \\
\hline 1.25 & 58 & Use informative subheadings for long copy. \\
\hline 1.25 & 24 & Use wordplay if it is clearly related to the product. \\
\hline 1.23 & 26 & Avoid negative words unless the target market believes the opposite. \\
\hline
\end{tabular}




\section{TABLE 1 ( cont'd)}

\begin{tabular}{|c|c|c|}
\hline Recall & $\begin{array}{l}\text { Number of } \\
\text { Advertising } \\
\text { Pairs }\end{array}$ & Description of Principles: I ncludes Necessary Conditions \\
\hline 1.21 & 42 & Describe specific, meaning \\
\hline 1.21 & 26 & Show that people similar to those in the target market use the product. \\
\hline 1.21 & 13 & Match the facial expression of the spokesperson to the product and target market. \\
\hline 1.19 & 43 & When using an explicit action step, make it easy. \\
\hline 1.19 & 19 & Lead the reader into the body copy. \\
\hline 1.17 & 24 & Alert the target market early. \\
\hline 1.17 & 41 & Consider using visuals that create favorable associations with the product. \\
\hline 1.16 & 30 & Use a single theme-or two in some situations. \\
\hline 1.15 & 73 & Demonstrate product benefits. \\
\hline 1.14 & 45 & Use positive innuendos when their use has a basis. \\
\hline 1.14 & 43 & For high-involvement advertisements based on strong arguments, do not write on pictures. \\
\hline 1.14 & 52 & Repeat the main message at the end of the advertisement. \\
\hline 1.14 & 34 & Use blank spaces between paragraphs to add emphasis and to aid scanability. \\
\hline 1.13 & 65 & Include information on when, where, and how to buy the product. \\
\hline 1.13 & 36 & Make the first paragraph short. \\
\hline 1.12 & 46 & When using a picture, relate it to the headline. \\
\hline 1.11 & 118 & Use long headlines for High Involvement products. \\
\hline 1.11 & 38 & Provide high typeface and background contrast for informative text. \\
\hline 1.11 & 37 & Use a personal tone only with strong arguments. \\
\hline 1.10 & 29 & Use words that enhance the purchasing and consuming experience (adjectives in headlines) \\
\hline 1.10 & 26 & In a long-term advertising program, emphasize brand identifiers. \\
\hline 1.08 & 25 & Use columns for informative text with long copy. \\
\hline 1.08 & 17 & Avoid large pictures in advertisements with information. \\
\hline 1.08 & 11 & Avoid upper case and bold for informative text with three or more lines. \\
\hline 1.07 & 31 & Keep the headline short for low involvement products \\
\hline 1.07 & 28 & Consider using concrete metaphors that are related to a benefit \\
\hline 1.06 & 16 & Use color to provide information \\
\hline 1.01 & 45 & Use power words if they fit the product. \\
\hline 1.00 & 30 & Use a slogan or tagline if a USP exists. \\
\hline
\end{tabular}


Norland advertisement that based its USP on "an uncommon concern for quality."

The advertisements and the results of the coding are provided at www.advertisingprinciples.com. The ratings of the advertisements along with the copy-testing scores are available upon request to those who might want to conduct replications or further analyses.

\section{Analysis}

Our primary analysis involved comparing advertisements using the principle of interest to matched advertisements that did not. Of course, if all advertisers followed the principles, we would have little to be talking about. Fortunately (for us), a large proportion of advertisements violate principles.

We were able to use the quasiexperimental analysis for 56 principles, using the advertising principles from $\mathrm{Per}$ suasive Advertising (Armstrong, forthcoming). We listed them in order of their importance (see Table 1). The necessary conditions are included in the statements.

The recall gain ratios can be interpreted as percentages. (For example, the 1.74 for the third principle means that advertisements that followed the principle had 74 percent higher recall than their matched advertisements that did not follow the principle.) The number of pairs analyzed differed for each principle and is reported in Table 1.

Of the 56 principles that we tested, on average, there was a 24 percent relative gain in recall. For example, we found that the average recall score for the advertisements that included both the brand and the company name was 24 percent versus 14 percent for the other advertisements-which works out to a 71 percent gain in recall.

\section{Testing conditions}

In some cases, the quasi-experimental analyses helped us test certain conditions that we had hypothesized to be important. For example, we initially tested the principle "Keep the headline short" in the $W A P B$ 5th edition and found no benefit. We then reasoned that this might not hold for high-involvement products with strong arguments and conducted further tests. This subsequent analysis of all five editions of WAPB found 31 pairs of lowinvolvement print advertisements where the number of words in headlines in each pair differed by two or more; here, recall for advertisements with shorter headlines was 1.07 times better. But for the 118 pairs of advertisements for high-involvement products, the result was reversed. In this case, recall for advertisements with longer headlines was 1.11 times greater.

The analyses also helped to refine or eliminate principles being considered. For one principle that was considered, "Include a verb in the headline," we relied on the reasoning of advertising experts. The WAPB analysis produced results that contradicted that principle. We then went back to the prior literature and found a study with evidence that verbs should not be used (Rossiter, 1981). Ultimately, we dropped this principle due to weak evidence. In another principle, "Avoid negative words in the headline," we again failed to find an effect. Once again, an empirical study found that there was a key condition we overlooked-namely, negative words are useful when used in headlines to refute a common belief (Rossiter, 1981).

\section{VALIDITY TESTS FOR THE QUASI-EXPERI MENTAL ANALYSES}

To examine the validity of our findings from the quasi-experimental analysis, we compared these findings to those from experimental data. There are some challenges in making such comparisons. The quasi-experimental analyses relied on recall measures; different criteria, however, were used in the experimental data (e.g., intentions to purchase, sales, or product ratings). Also, the number of pairs for the quasi-experimental data was relatively small, ranging in size from 6 to 118, with an average of 31 pairs of advertisements. Finally, some of the experiments were based on small samples.

Despite these concerns, the findings from the quasi-experimental analyses were in agreement with respect to:

- all seven principles for which we had meta-analyses;

- all 27 principles for which we had lab experiments;

- all seven principles for which we had field experiments.

Given this demonstrated validity of the quasi-experimental analyses, we have gained knowledge of about 56 advertising principles and about their persuasiveness. We also have confidence in the 27 principles for which the WAPB analyses provided the only experimental evidence.

The data we used had been obtained originally for other purposes. Thus, there was no cost for data gathering, and the costs for coding and data analysis were modest as well.

What about nonexperimental analyses? Do they provide valid results? There were 24 principles for which we were able to compare the findings of nonexperimental data with experimental findings; they differed in 8 of the 24 principles (33 percent). Thus analyses of nonexperimental data pertaining to advertising principles should be viewed with caution.

\section{CONCLUSIONS}

The quasi-experimental analysis represents a low-cost approach to improve and validate persuasive principles. This 
validation study also provides assurance that an advertising principle can be relied on when the support is limited to quasiexperimental analyses.

1. Scott Armstrong is a Professor of Marketing at the Wharton School, University of Pennsylvania.

Sandeep Patnaik is the Research Director at Gallup and Robinson in Pennington, NJ.

\section{ACKNOWLEDGMENTS}

Gerry Lukeman and Malcolm Wright provided useful comments and Max Feldman edited the paper.

\section{REFERENCES}

Armstrong, J. Scott. Persuasive Advertising. New York: Palgrave Macmillan, forthcoming.
Burton, Philip Ward, and Scott C. Purvis. Which Ad Pulled Best? 5th through 9th editions. Chicago, IL: Crain Books, 1987-2002.

Rossiter, John. "Predicting Starch Scores." Journal of Advertising Research 21, 5 (1981): 63-68.

Zinkhan, George M., and Betsy D. Gelb. "What Starch Scores Predict." Journal of Advertising Research 26, 4 (1986): 45-50. 